РОЗРОБЛЕННЯ ТА МАТЕМАТИЧНЕ ОПРАЦЮВАННЯ РЕЗУЛЬТАТІВ ТЕСТІВ З ДИСЦИПЛІНИ «АНГЛІЙСЬКА МОВА (ЗА ПРОФЕСІЙНИМ СПРЯМУВАННЯМ)» ДЛЯ СТУДЕНТІВ ЕКОЛОГІЧНИХ СПЕЦІАЛЬНОСТЕЙ ЗВО

\title{
ELABORATION AND MATHEMATICAL PROCESSING OF TEST RESULTS ON "ENGLISH LANGUAGE (FOR SPECIFIC PURPOSE)" FOR STUDENTS OF ECOLOGICAL SPECIALITIES OF HEI
}

УДК 372.8:378.02

DOI https://doi.org/10.32843/2663-

$6085 / 2021 / 32-2.12$

\section{Бондаренко 3.В.,}

канд. пед. наук, доцент,

доцент кафедри вищої математики

Вінницького національного технічного університету

\section{Слободянюк А.А.,}

старший викладач кафедри іноземних мов

Вінницького національного технічного університету

Кирилащук С.A., канд. пед. наук, доцент, доцент кафедри вищої математики Вінницького національного технічного університету
Стаття присвячена актуальним проблемам використання тестів у навчальному процесі ЗВО. Тестування надійно увійшло у світову педагогічну практику. В Україні цей процес також набуває сил, адже розвиваються уявлення про призначення та педагогічні можливості тестів, фрорми тестів, формати залитань, методи оброблення результатів тестування та їх інтерпретації. Відомо, що тільки правильно складений тест дає можливість повністю відповідати сучасним цілям навчання й освіти.

Багато викладачів мають певні труднощі в розробленні таких тестів та їх правильному методичному застосуванні. Таким чином, можна констатувати, що в цьому аспекті необхідні певні рекомендації. Факт відсутності в немовних ЗВО України уніррікованої системи оцінювання рівня володіння мовою підтверджується результатами інтерв'ю 3 викладачами англійської мови профресійного спрямування.

Отже, розроблення тесту з англійської мови неможливо відокремити від математичного опрацювання результатів тестів і визначення якості створюваного тесту, тому названі три проблеми об'єднані у статmі й розглядаються фраховим колективом авторів одна за одною в ході роботи зі створення тесту. В результаті дослідження проведено математичний розрахунок основних показників тесту, а також визначено якість розробленого тесту.

у статті викладено основні ідеї розроблення тесту закритого типу з дисципліни «Англійська мова (за профресійним спрямуванням)» для студентів спеціальностей «Екологія», «Технології захисту навколишнього середовища».

Курс передбачає вивчення основних понять з екології та накопичення лексичного матеріалу з екологічної тематики, формування умінь використовувати навчальний матеріал для своєї майбутньої спеціальності англійською мовою. Отримання таких знань $\epsilon$ важливою задачею, оскільки нині студентам з України надається унікальна можливість проходити стажування та стати затребуваними фрахівцями в Європейському середовищі на тлі серйозних екологічних проблем, з якими стикається людство сьогодення.
Ключові слова: тести, англійська мова, екологічні спеціальності, надійність тесту, валідність тесту, коефіцієнт кореляції.

The article is devoted to actual problems of using tests in the educational process of higher education institutions. Testing has reliably entered the world pedagogical practice. In Ukraine, this process is also gaining strength: ideas about the purpose and pedagogical capabilities of tests, test forms, question formats, methods of processing test results and their interpretation are being developed. It is known that only a correctly made up test allows the complete correspondence to the modern purposes of training and education.

Many teachers have some difficulty in developing such tests and their proper methodological application. Thus, it can be stated that certain recommendations are necessary in this regard. The fact that the non-language higher education institutions of Ukraine do not have a unified system for assessing the language proficiency level is confirmed by the results of interviewing teachers of English language for specific purpose.

Therefore, the elaboration of an English test cannot be separated from the mathematical processing of test results and determining the quality of the created test. Hence, three described problems are combined in this article and are considered one after another by a professional team of authors in the course of working out the test. As a result of research the mathematical calculation of the basic test indicators is carried out, and also the quality of the elaborated test is defined.

The article presents the main ideas of elaborating a closed-type test on "English Language (for Specific Purpose)" for specialties in "Ecology", "Environmental Protection Technology".

The course involves learning basic concepts of ecology and accumulation of lexical material on ecological topics, formation of skills to use educational material for their future specialty in English. Obtaining such knowledge is an important task because nowadays students from Ukraine have a unique opportunity for internship and becoming in-demand professionals in the European environment against the backdrop of serious ecological problems facing humanity today.

Key words: tests, English language, ecological specialties, test reliability, test validity, correlation coefficient.
Постановка проблеми у загальному вигляді. Згідно з останніми тенденціями, коли виникає вимушена й нагальна потреба дистанційного навчання, фрормування навчальних планів та програм, значна частина навчального матеріалу передбачають самостійне опрацювання та вивчення студентами окремих тематичних розділів, що, на жаль, дещо знижує якість їх засво- єння. Хоча рівень знань студентів значною мірою залежить від особистих зусиль і здібностей, формування системи або структури знань залежить від правильної організації навчального процесу, зокрема від організації самостійної роботи, поточного й підсумкового контролю знань [1]. У зв'язку з цим актуальними стають питання розроблення таких засобів організації самостійної роботи сту- 
дентів, які сприятимуть підвищенню якості засвоєння студентами навчального матеріалу. Одним із таких засобів є тестування.

Аналіз останніх досліджень і публікацій. Останнім часом, на думку багатьох дослідників (С.Ю. Ніколаєва, І.В. Коломієць, Х. Дуглас Браун, Дж. Хант, М. Гронланд), одним із найбільш ефективних способів контролю під час вивчення іноземної мови є тест. Питання розроблення та застосування тестів для контролю та оцінювання знань розглядалося багатьма вітчизняними та зарубіжними дослідниками, такими як О.О. Молокович [2], С.Ю. Ніколаєва, О.П. Петращук, J. Charles Alderson, Lyle Bachman [3], Douglas Brown [4].

Виділення не вирішених раніше частин загальної проблеми. Факт відсутності в немовних ЗВО України уніфрікованої системи оцінювання рівня володіння мовою підтверджується результатами інтерв'ю $з$ викладачами англійської мови профресійного спрямування. Респонденти зазвичай користуються такими підходами до розроблення матеріалів контролю та оцінювання знань студентів:

1) запозичення тестових матеріалів із підручників;

2) запозичення готових тестових матеріалів із різних видань, безкоштовних зразків та наведених тестів в Інтернеті;

3) запозичення готових тестів для перевірки прогресу у вивченні підручників;

4) адаптування автентичних матеріалів самостійно.

Усі наведені підходи мають свої недоліки. Перші три підходи, незважаючи на те, що передбачають тести, розроблені професіоналами, мають ризик невідповідності потребам студентів, які вивчають англійську мову профресійного спрямування (потребам, специфрічним у кожному окремому випадку), цілям курсу, матеріалам та оцінюванню. Якщо немає підручника, який би абсолютно відповідав усім потребам студентів та цілям курсу, то безглуздо вживати запозичений 3 підручника тест, розроблений для іншого контексту вивчення англійської мови професійного спрямування, тому що іспит не буде відображати принципи й цілі навчання, які, як передбачається, він повинен виміряти. Другий недолік наявний під час використання четвертого підходу до розроблення тестів, який практикується в немовних ЗВО України, а саме адаптування автентичних матеріалів до конкретних потреб та цілей контролю. Ця робота вимагає від викладача англійської мови проходження відповідного тренінгу із сучасних принципів контролю та оцінювання й принципів складання тестів. На жаль, українські викладачі англійської мови професійного спрямування не мають таких знань [5]. Отже, розроблення тесту 3 англійської мови неможливо відокремити від мате- матичного опрацювання результатів тестів і визначення якості створюваного тесту, тому окреслені три проблеми об'єднані у статті і розглядаються фаховим колективом авторів одна за одною в ході роботи зі створення тесту.

Мета статті полягає в описі цілей і змісту розробленого тесту, який пов'язаний з визначенням тих якостей, які повинні бути сорормованими в результаті навчання студентів (повнота, глибина, узагальненість, усвідомленість); проведенні математичного розрахунку основних показників тесту; визначенні якості розробленого тесту.

Виклад основного матеріалу. На кафедрі іноземних мов Вінницького національного технічного університету розроблено тест закритого типу з дисципліни «Англійська мова (за профресійним спрямуванням)» для студентів спеціальностей «Екологія», «Технології захисту навколишнього середовища». Курс передбачає вивчення основних понять з екології та накопичення лексичного матеріалу 3 екологічної тематики, фрормування умінь використовувати навчальний матеріал для своєї майбутньої спеціальності англійською мовою. Отримання таких знань є важливою задачею, оскільки нині студентам з України надається унікальна можливість проходити стажування та стати затребуваними фахівцями в Європейському середовищі на тлі серйозних екологічних проблем, 3 якими стикається людство сьогодення. Однак навіть добре мотивований студент також потребує контролю знань на кожному етапі навчання, що $€$ його невід'ємною частиною. Отримавши результати тестування, викладач має унікальну інформацію про якість засвоєння навчального матеріалу 3 англійської мови, що дає йому змогу вчасно скорегувати весь процес навчання, а це допомагає його ефрективності та раціоналізації.

Завдання тесту супроводжуються інструкцією «Виберіть правильну відповідь». Будуються завдання у вигляді стверджувального речення, закінченням якого є варіанти відповіді. Всі варіанти правдоподібні і рівноправні, але тільки один з них є правильним. Відповіді будуються за алфавітом або розташовані довільним чином. Нижче наведені два тестових завдання 3 відповідною побудовою відповідей [6].

Приклад 1.

Large-scale commercial hunting and sale of wild animal's pushes species to the...

a) +brink of extinction;

b) crop damage;

c) forest management;

d) healthy forest ecosystems;

e) maintaining ecosystems.

Приклад 2.

There are world-wide ways to use controlled fires for preventing unpredictable...

a) pesticides; 
b) crop damage;

c) species;

d) +wildfires;

e) ecosystems.

В процесі опрацювання тесту не існує порядку, в якому розташовуються завдання. Цей порядок не $€$ фріксованим і не залежить від того, як відповідає студент. Процес контролю припускає, що студент повинен відповідати на всі завдання, тобто вибір наступного завдання не залежить від відповіді на попереднє. Кожне завдання тесту висвітлює лексичний матеріал 3 екологічної тематики, який було запропоновано студентам для практичного оволодіння. Всі необхідні елементи знань та умінь враховано в процесі контролю. Деякі завдання тесту розраховано на перевірку засвоєння конкретних дефініцій і вимагають конкретних знань. Наприклад, у наступному прикладі студентам запропоновано визначити назву науки, яка вивчає взаємозв'язок між організмами та їх навколишнім середовищем.

Приклад 3.

...is the study of interactions among organisms and their environments.
a) biosphere;
b) +ecology;
c) habitat;
d) ecosystem;
e) surface.

Декілька завдань тесту складаються 3 більш змістовно-комплексного наповнення відповідей, що ускладнює завдання студента визначитися 3 вибором правильної відповіді.

Приклад 4.

Plants obtain elements from the surrounding...

a) reproduction, development, behavior;

b) carbon, nitrogen, phosphorus;

c) extinction, population, species;

d) +atmosphere, water, soils;

e) organic molecules, cellular processes, photosynthesis.

В процесі вивчення будь-якої іноземної мови повноцінне спілкування неможливо без граматики, оскільки оволодіння граматичним матеріалом $€$ невід'ємною частиною всіх видів мовленнєвої діяльності. Нижче наведено приклади з лексичним наповненням та на певні правила $з$ граматики.

Приклад 5.

They saw some kangaroos but they ... any crocodiles.
a) +did not see;
b) see;
c) saw;
d) did not saw.
Приклад 6.

Mark enjoyed swimming peacefully and ... at all the sharks.

a) look; b) +looking;

c) looks;

d) to look.

Під час складання тестових завдань слід обов'язково враховувати певні вимоги. Студенти не повинні замислюватися, як тлумачити надану в реченні інформацію. Вважається неправильним допускати вільне інтерпретування речення, має бути виключена можливість багатозначних відповідей. В наступному прикладі студентам пропонується прочитати коротку інорормацію про екосистему й дати однозначну відповідь на поставлене питання «правильно/неправильно».

Приклад 7.

When we think of nature we usually think of living things such as plants and animals. The biotic components of an ecosystem include all the living things in an area.

This is a monarch butterfly and this is a tiger swallowtail butterfly. You decide why these butterflies are different from each other. These butterflies are members of two different species. A species consists of a group of organisms which can successfully reproduce among them. Members of the same species possess similar characteristics. They often appear and behave similarly like these Canada geese.

A group of the same species in the same area is called a population. For example, the water lilies in this pond make up a water lily population. And the geese in this field make up a population, as do the turtles in this pond.

a) Thinking about nature we imagine animals and plants. (T)

b) The biotic components of an ecosystem do not include all the living things in an area. $(F)$

c) A monarch butterfly and a tiger swallowtail butterfly are different. $(\mathrm{T})$

d) Members of the same species have the same characteristics. ( $T$ )

e) A population does not mean a group of the same species in the same area. $(F)$

Підбираючи тестові завдання, викладач враховує їх відповідність вивченому навчальному матеріалу. Наступний приклад передбачає знання й розуміння лексики студентом та полягає в тому, щоб до кожного початку речення підібрати одне можливе правильне закінчення цього речення.

Приклад 8.

\begin{tabular}{|l|l|}
\hline $\begin{array}{l}\text { 1. Plants, animals, and other } \\
\text { life forms on the Earth }\end{array}$ & $\begin{array}{l}\text { a) of any terrestrial } \\
\text { biome. }\end{array}$ \\
\hline $\begin{array}{l}\text { 2. Ecosystems can be as } \\
\text { small as a flea's intestines }\end{array}$ & $\begin{array}{l}\text { b) and their relationship to } \\
\text { their environments. }\end{array}$ \\
\hline $\begin{array}{l}\text { 3. The entire Earth is also an } \\
\text { ecosystem, }\end{array}$ & $\begin{array}{l}\text { c) live together in } \\
\text { ecosystems. }\end{array}$ \\
\hline $\begin{array}{l}\text { 4. Biomes encompass all of } \\
\text { the ecosystems }\end{array}$ & d) as the food chain. \\
\hline $\begin{array}{l}\text { 5. Tropical rain forests have } \\
\text { the most biodiversity }\end{array}$ & $\begin{array}{l}\text { e) or as large as the } \\
\text { Amazon basin. }\end{array}$ \\
\hline
\end{tabular}




\begin{tabular}{|l|l|}
\hline $\begin{array}{l}\text { 6. Coral reefs are the most } \\
\text { diverse }\end{array}$ & $\begin{array}{l}\text { I) or herbivores, the plant- } \\
\text { eating animals. }\end{array}$ \\
\hline $\begin{array}{l}\text { 7. Ecosystems provide } \\
\text { services to the planet }\end{array}$ & $\begin{array}{l}\text { g) therefore, ecosystems } \\
\text { can be nested inside } \\
\text { each other. }\end{array}$ \\
\hline $\begin{array}{l}\text { 8. Ecology is the study of the } \\
\text { distribution and abundance } \\
\text { of species }\end{array}$ & $\begin{array}{l}\text { k) are primary producers, } \\
\text { mostly photosynthesizes. }\end{array}$ \\
\hline $\begin{array}{l}\text { 9. One of the primary } \\
\text { concerns of ecologists is }\end{array}$ & $\begin{array}{l}\text { i) that have similar climate } \\
\text { and organisms. }\end{array}$ \\
\hline $\begin{array}{l}\text { 10. This passing of energy is } \\
\text { described }\end{array}$ & $\begin{array}{l}\text { j) of any ocean } \\
\text { ecosystem. }\end{array}$ \\
\hline $\begin{array}{l}\text { 11.At the base of every food } \\
\text { chain (the first trophic level) }\end{array}$ & $\begin{array}{l}\text { h) and all of its } \\
\text { inhabitants. }\end{array}$ \\
\hline $\begin{array}{l}\text { 12.The second trophic level } \\
\text { is inhabited by primary } \\
\text { consumers }\end{array}$ & $\begin{array}{l}\text { f) how food energy is } \\
\text { passed from organisms } \\
\text { at one trophic level to } \\
\text { organisms at the next } \\
\text { trophic level. }\end{array}$ \\
\hline
\end{tabular}

В тестуванні, яке містило 52 питання, брали участь 150 студентів у результаті декількох випробувань. Опрацювання тесту почалось із побудови матриці результатів [7].

Наведемо приклад, коли студенти контролювалися за допомогою тесту, що містив 12 завдань (перша частина тесту з теми). В табл. 1 наведена відповідна цьому випадку матриця результатів. Матриця має розмірність $\mathrm{M} \times \mathrm{N}$, де $\mathrm{M}-$ кількість завдань, N - кількість випробовуваних. Як видно, елементами матриці $x_{i j}$, де $i$ - номер випробовуваного (рядки), $j$ - номер завдання (стовпця), $€$ нулі та одиниці; 1 означає, що відповідь правильна, 0 - відповідь неправильна.

Для кожного студента визначено сумарний бал $x_{i}=\sum_{j=1}^{M} x_{i j}$, що визначає успішність, а для кожного завдання - кількість правильних відповідей $R_{j}=\sum_{j=1}^{N} x_{i j}$ і кількість неправильних відповідей $W_{j}=N-R_{j}$. Величина $W_{i}$ визначає міру важкості j-го завдання.
Описані дані дали можливість побудувати упорядковану матрицю (табл. 2), у якій студенти розташовуються за їх успішністю (зверху вниз), а завдання - за їх складністю (зліва направо).

Як видно, упорядкована матриця є сукупністю двох трикутних матриць, що складаються 3 невеликими відхиленнями, одна - 3 нулів, інша - 3 одиниць. Всі завдання спроможні, тобто немає випадкових правильних відповідей і випадково неправильних.

Далі проводився розрахунок показників зв'язку завдань між собою і 3 сумою балів студентів. Основу цього складає коефріцієнт кореляції Пірсона $r_{y z}$, який визначався за такою фрормулою:

$$
r_{y z}=\frac{S P_{y z}}{\sqrt{S S_{y} \cdot S S_{z}}}
$$

де $y$ i $z$ - параметри, зв'язок між якими обчислюється; $S P_{y z}$ - сума добутків відхилень $y$ і $z$ від їх середніх значень; $S S_{y}$ або $S_{z}$ - сума квадратів відхилень по у або $z$ від його середнього значення.

Для визначення цих величин використано таку орормулу:

$$
S S_{y}=S S_{x_{i k}}=\sum_{i=1}^{N} x_{i k}{ }^{2}-\frac{\left(\sum_{i=1}^{N} x_{i k}{ }^{2}\right)^{2}}{N} .
$$

Для визначення зв'язку між k-м завданням і сумою балів використано таку фрормулу:

$$
S S_{z}=S S_{X_{i}}=\sum_{i=1}^{N} X_{i}^{2}-\frac{\left(\sum_{i=1}^{N} X_{i}\right)^{2}}{N} .
$$

Для визначення зв'язку між $k$-м і $m$-м завданням використано таку фрормулу:

$$
S S_{z}=S S_{x_{i m}}=\sum_{i=1}^{N} x_{i m}{ }^{2}-\frac{\left(\sum_{i=1}^{N} x_{i m}\right)^{2}}{N} .
$$

\begin{tabular}{|c|c|c|c|c|c|c|c|c|c|c|c|c|c|c|}
\hline \multirow[b]{2}{*}{ № } & \multirow[b]{2}{*}{ Код студента } & \multicolumn{12}{|c|}{ Номер завдання в тесті, $j$} & \multirow{2}{*}{$X_{i}$} \\
\hline & & 1 & 2 & 3 & 4 & 5 & 6 & 7 & 8 & 9 & 10 & 11 & 12 & \\
\hline 1 & 1 & 1 & 0 & 0 & 1 & 0 & 1 & 1 & 0 & 0 & 0 & 1 & 0 & 5 \\
\hline 2 & 2 & 1 & 0 & 1 & 0 & 1 & 1 & 0 & 0 & 1 & 0 & 1 & 1 & 7 \\
\hline 3 & 3 & 1 & 1 & 0 & 1 & 0 & 1 & 1 & 1 & 0 & 1 & 1 & 0 & 8 \\
\hline 4 & 4 & 1 & 1 & 1 & 1 & 1 & 0 & 1 & 0 & 1 & 0 & 0 & 1 & 8 \\
\hline 5 & 5 & 1 & 1 & 1 & 1 & 1 & 1 & 1 & 1 & 1 & 1 & 1 & 1 & 12 \\
\hline 6 & 6 & 1 & 0 & 0 & 1 & 1 & 1 & 1 & 1 & 1 & 0 & 1 & 0 & 8 \\
\hline 7 & 7 & 1 & 1 & 1 & 1 & 1 & 0 & 0 & 1 & 1 & 1 & 1 & 1 & 10 \\
\hline 8 & 8 & 1 & 1 & 0 & 1 & 0 & 0 & 0 & 0 & 1 & 1 & 0 & 1 & 6 \\
\hline 9 & 9 & 1 & 1 & 1 & 1 & 0 & 0 & 1 & 0 & 1 & 0 & 0 & 1 & 7 \\
\hline 10 & 10 & 0 & 1 & 1 & 0 & 1 & 0 & 1 & 0 & 1 & 1 & 0 & 1 & 7 \\
\hline \multicolumn{2}{|r|}{$R_{j}$} & 9 & 7 & 6 & 8 & 6 & 5 & 7 & 4 & 8 & 5 & 6 & 7 & \\
\hline \multicolumn{2}{|r|}{$W_{j}$} & 1 & 3 & 4 & 2 & 4 & 5 & 3 & 6 & 2 & 5 & 4 & 3 & \\
\hline
\end{tabular}

\section{Матриця результатів тестування}

Таблиця 1 
Упорядкована матриця результатів тестування

\begin{tabular}{|c|c|c|c|c|c|c|c|c|c|c|c|c|c|c|}
\hline \multirow[b]{2}{*}{ № } & \multirow[b]{2}{*}{ Код студента } & \multicolumn{12}{|c|}{ Номер завдання в тесті, $j$} & \multirow{2}{*}{$X_{i}$} \\
\hline & & 1 & 2 & 3 & 4 & 5 & 6 & 7 & 8 & 9 & 10 & 11 & 12 & \\
\hline 1 & 1 & 1 & 1 & 0 & 0 & 1 & 0 & 0 & 0 & 1 & 1 & 0 & 0 & 5 \\
\hline 2 & 2 & 1 & 1 & 1 & 1 & 0 & 1 & 0 & 0 & 0 & 0 & 1 & 0 & 6 \\
\hline 3 & 3 & 1 & 0 & 1 & 0 & 0 & 1 & 1 & 1 & 1 & 1 & 0 & 0 & 7 \\
\hline 4 & 4 & 1 & 1 & 1 & 1 & 1 & 1 & 1 & 0 & 0 & 0 & 0 & 0 & 7 \\
\hline 5 & 5 & 0 & 0 & 1 & 1 & 1 & 1 & 1 & 1 & 0 & 0 & 1 & 0 & 7 \\
\hline 6 & 6 & 1 & 1 & 0 & 1 & 1 & 0 & 0 & 0 & 1 & 1 & 1 & 1 & 8 \\
\hline 7 & 7 & 1 & 1 & 1 & 1 & 1 & 1 & 1 & 1 & 0 & 0 & 0 & 0 & 8 \\
\hline 8 & 8 & 1 & 1 & 1 & 0 & 1 & 0 & 0 & 1 & 1 & 1 & 0 & 1 & 8 \\
\hline 9 & 9 & 1 & 1 & 1 & 1 & 0 & 1 & 1 & 1 & 1 & 0 & 1 & 1 & 10 \\
\hline 10 & 10 & 1 & 1 & 1 & 1 & 1 & 1 & 1 & 1 & 1 & 1 & 1 & 1 & 12 \\
\hline \multicolumn{2}{|r|}{$W_{j}$} & 1 & 2 & 2 & 3 & 3 & 3 & 4 & 4 & 4 & 5 & 5 & 6 & \\
\hline \multicolumn{2}{|c|}{$\begin{array}{c}\text { Старий номер } \\
\text { завдання }\end{array}$} & 1 & 4 & 9 & 2 & 7 & 12 & 3 & 5 & 11 & 6 & 10 & 8 & \\
\hline
\end{tabular}

Кореляційна матриця

Таблиця 3

\begin{tabular}{|c|c|c|c|c|c|c|c|c|c|c|c|c|c|}
\hline$i$ & 1 & 2 & 3 & 4 & 5 & 6 & 7 & 8 & 9 & 10 & 11 & 12 & $r_{x_{i j} x_{i}}$ \\
\hline 1 & 1,00 & 0,71 & $-0,12$ & $-0,23$ & $-0,23$ & $-0,22$ & $-0,33$ & $-0,32$ & 0,44 & 0,34 & 0,31 & 0,34 & 0,22 \\
\hline 2 & 0,71 & 1,00 & $-0,32$ & 0,22 & 0,22 & $-0,31$ & $-0,41$ & $-0,41$ & 0,14 & 0,00 & 0,00 & 0,44 & 0,21 \\
\hline 3 & $-0,12$ & $-0,32$ & 1,00 & 0,23 & $-0,33$ & 0,72 & 0,64 & 0,64 & 0,41 & 0,52 & 0,45 & $-0,12$ & 0,34 \\
\hline 4 & $-0,23$ & 0,22 & 0,23 & 1,00 & 0,76 & 0,58 & 0,42 & $-0,11$ & 0,52 & 0,63 & 0,75 & 0,89 & 0,39 \\
\hline 5 & $-0,23$ & 0,22 & $-0,33$ & 0,76 & 1,00 & $-0,41$ & $-0,12$ & $-0,12$ & $-0,12$ & 0,25 & $-0,13$ & 0,26 & 0,05 \\
\hline 6 & $-0,22$ & $-0,31$ & 0,72 & 0,58 & $-0,41$ & 1,00 & 0,87 & 0,49 & 0,52 & 0,64 & 0,27 & 0,44 & 0,37 \\
\hline 7 & $-0,33$ & $-0,41$ & 0,64 & 0,42 & $-0,12$ & 0,87 & 1,00 & 0,66 & 0,47 & 0,38 & 0,56 & $-0,23$ & 0,46 \\
\hline 8 & $-0,32$ & $-0,41$ & 0,64 & $-0,11$ & $-0,12$ & 0,49 & 0,66 & 1,00 & 0,89 & 0,30 & 0,80 & 0,36 & 0,57 \\
\hline 9 & 0,44 & 0,14 & 0,41 & 0,52 & $-0,12$ & 0,52 & 0,47 & 0,89 & 1,00 & 0,86 & 0,30 & 0,79 & 0,74 \\
\hline 10 & 0,34 & 0,00 & 0,52 & 0,63 & 0,25 & 0,64 & 0,38 & 0,30 & 0,86 & 1,00 & $-0,22$ & 0,84 & 0,71 \\
\hline$\overline{r_{j}}$ & 0,10 & 0,08 & 0,34 & 0,40 & 0,09 & 0,30 & 0,36 & 0,30 & 0,51 & 0,49 & 0,30 & 0,40 & \\
\hline
\end{tabular}

Величина $S P_{\text {уz }}$ обчислюється таким чином:

$$
S P_{y z}=S P_{x_{i k}}=\sum_{i=1}^{N} x_{i m} z-\frac{\sum_{i=1}^{N} x_{i m} \sum_{i=1}^{N} z}{N} .
$$

На підставі результатів розрахунків побудована кореляційна матриця (табл. 3), компонентами якої $€$ коесріцієнти зв'язків між завданнями. Крім того, розраховані коефіцієнти зв'язків усіх завдань із сумою балів для кожного студента.

В таблиці обчислено середній коефіцієнт кореляції завдання з усіма завданнями. Нормою вважається значення коефіцієнта кореляції не нижче 0,3. В цьому разі тест валідний за здатністю диференціювати студентів [8]. Видно, що цьому критерію не відповідають завдання № 1, № 2, № 5. Ці завдання були виключені з тесту. В табл. 4 наведено матрицю після вилучення, яка отримана 3 матриці (табл. 3) шляхом виключення завдань № 1 , № 2, № 5 .

Видно, що всі коефіцієнти кореляції збільшили свої значення.
Для визначення точності вимірювання рівня підготовленості студентів відповідно до контрольованих параметрів було проведено оцінювання надійності тесту за коефіцієнтом кореляції:

$$
r_{i}=\frac{M \cdot \bar{R}}{1+(M-1) \bar{R}} .
$$

де $\bar{R}$ - середнє значення середніх коефіцієнтів кореляції завдань тесту між собою:

$$
\bar{R}=\frac{\sum_{j=1}^{M} \bar{r}_{j}}{M} .
$$

Для надійності тесту коефіцієнт кореляції повинен перевищувати 0,8 [9].

Для тесту, з якого вилучили завдання (матриця табл. 4), фрормули (6) і (7) дають значення $r_{i}=0,92$. Для тесту, з якого завдання не вилучали (матриця табл. 3), значення $r_{i}$ менше: $r_{i}=0,85$. Таким чином, вилучення завдань № 1, № 2, № 5 із тесту підвищило його надійність.

Висновки. Отже, розроблений тест відповідає основним характеристикам тесту і може бути 
Кореляційна матриця після вилучення завдань

\begin{tabular}{|c|c|c|c|c|c|c|c|c|c|c|}
\hline $\mathrm{i}$ & 3 & 4 & 6 & 7 & 8 & 9 & 10 & 11 & 12 & $r_{x_{i j} x_{i}}$ \\
\hline 3 & 1,00 & 0,23 & 0,72 & 0,64 & 0,64 & 0,41 & 0,52 & 0,45 & $-0,12$ & 0,34 \\
\hline 4 & 0,23 & 1,00 & 0,58 & 0,42 & $-0,11$ & 0,52 & 0,63 & 0,75 & 0,89 & 0,39 \\
\hline 6 & 0,72 & 0,58 & 1,00 & 0,87 & 0,49 & 0,52 & 0,64 & 0,27 & 0,44 & 0,37 \\
\hline 7 & 0,64 & 0,42 & 0,87 & 1,00 & 0,66 & 0,47 & 0,38 & 0,56 & $-0,23$ & 0,46 \\
\hline 8 & 0,64 & $-0,11$ & 0,49 & 0,66 & 1,00 & 0,89 & 0,30 & 0,80 & 0,36 & 0,57 \\
\hline 9 & 0,41 & 0,52 & 0,52 & 0,47 & 0,89 & 1,00 & 0,86 & 0,30 & 0,79 & 0,74 \\
\hline 10 & 0,52 & 0,63 & 0,64 & 0,38 & 0,30 & 0,86 & 1,00 & $-0,22$ & 0,84 & 0,71 \\
\hline $\bar{r}_{j}$ & 0,59 & 0,47 & 0,68 & 0,63 & 0,55 & 0,66 & 0,61 & 0,41 & 0,42 & \\
\hline
\end{tabular}

використаний на заняттях 3 англійської мови за професійним спрямуванням для студентів екологічних спеціальностей. По-перше, це можливість охоплення всього обсягу навчального матеріалу з урахуванням усіх мовних аспектів. По-друге, під час виконання тестових завдань створено однакові умови контролю для всіх студентів. Систематичне використання цього тесту підтверджують результативність та переваги такого методу роботи, що дає змогу швидко та якісно оцінювати знання студентів, за необхідності вносити корективи в навчальний процес.

\section{БІБЛІОГРАФІЧНИЙ СПИСОК:}

1. Бондаренко 3.В. та ін. Особливості тестування студентів під час дистанційної форми навчання вищої математики в технічному університеті. Педагогіка формування творчої особистості у вищій і загальноосвітній школах. 2020. № 73. Т. 1. С. 182-186.

2. Молокович О.О. Тестовий контроль рівня володіння говорінням англійською мовою як другою іноземною у студентів II курсу мовного фракультету : дис. ... канд. пед. наук : спец. 13.00.02 / Київський національний лінгвістичний університет. Київ, 2001. 243 с.
3. Brown H.D. Teaching by Principles : An Interactive Approach to Language Pedagogy. Longman, 2001. $480 \mathrm{p}$.

4. Cambridge Dictionaries Online : веб-сайт. URL: http://dictionary.cambridge.org (дата звернення: 15.12.2020).

5. Бойко Ю.В. Тест як один з видів контролю рівня володіння іноземною мовою у ВНЗ. Проблеми та перспективи розвитку науки на початку третього тисячоліття у країнах Європи та Азії : матеріали XVIII Міжнародної науково-практичної конференції, 29-30 грудня 2013 р. Переяслав-Хмельницький, 2013. С. 92-99.

6. Прадівлянний М.Г., Марченко М.Г., Слободянюк А.А. Англійська мова для студентів-екологів. ч. 1 : навчальний посібник. Вінниця, 2016. 60 с.

7. Бондаренко 3.В. Розроблення тестів для контролю знань і умінь студентів технічного ВН3 3 теми «Диференційні рівняння» Вісник ВПІ. 2004. № 3. URL: https://visnyk.vntu.edu.ua/index.php/visnyk/ article/view/43/43 (дата звернення: 22.12.2020).

8. Булах І.Є., Шило І.М. Мотивація навчання і валідизація оцінювання рівня знань. Педагогіка $i$ психологія. 1996. № 3. С. 125-129.

9. Генденштейн Л.Е. Як розробляти навчальні тести. Комп'ютер у школі та сім'ї. 2003. № 7. C. $39-40$. 